\title{
CASE REPORT: DANDY WALKER MALFORMATION WITH ASSOCIATED OCCIPITAL MENINGOCELE
}

\author{
Shrishail S. Patil ${ }^{1}$, Apoorva Rampure ${ }^{2}$
}

\section{HOW TO CITE THIS ARTICLE:}

Shrishail S. Patil, Apoorva Rampure. "Case Report: Dandy Walker Malformation with Associated Occipital Meningocele". Journal of Evolution of Medical and Dental Sciences 2014; Vol. 3, Issue 42, September 08; Page: $10443-10447$, DOI: $10.14260 /$ jemds/2014/3359

\begin{abstract}
A neonate presented with Dandy walker syndrome associated with occipital meningocele manifesting as soft tissue mass on the skull. Computed tomography demonstrated a large posterior fossa cyst communicating between fourth ventricle and occipital meningocele and dilated ventricular system (hydrocephalus).
\end{abstract}

KEYWORDS: meningocele, posterior fossa cyst, Dandy walker syndrome, hydrocephalus

INTRODUCTION: The Dandy-Walker syndrome is a congenital anomaly characterized by hydrocephalus, a posterior fossacyst, and absence of the cerebellar vermis.[1,2,3,6,7,10,13] This syndrome is well known, but only occurs in $4-8 \%$ of neonates with congenital hydrocephalus. ${ }^{[5,12]}$ The prognosis of this syndrome has been improved in the past 20 years by the establishment of therapeutic methods using shunt operations and suitable antibiotics, but the mortality is still high, ranging from 26 to $50 \% \cdot{ }^{[5,7,8,11]}$

One major cause of therapeutic problems and the poor prognosis is the frequent association with other central nervous system anomalies, in $1 / 3$ to $2 / 3$ of the cases.[8,10,11,13,15] We describe an infant with Dandy-Walker syndrome associated with an unusual giant occipital Meningocele.

CASE SUMMARY: A neonate presented with a soft tissue mass in the occipital region with enlarged head circumference. Patient was referred to the radiology department where he was subjected for the computed tomography of the head.

NECT REVEALED: A direct communication of the posterior fossa cyst with the occipital meningocele at one end and the fourth ventricle at the other end.

DISCUSSION: Abnormal cerebellar development causes a spectrum of disorders which can be classified into malformations of the paleocerebellum and neocerebellum(Altman et al., 1992).

Paleocerebellar malformations show vermian defects as key features, whereas malformations of the neocerebellum, including aplasia, hypoplasia and dysplasia, concern mainly the cerebellar hemispheres.

Dandy walker syndrome is a congenital brain malformation involving the cerebellum and the fluid filled spaces around it. A key feature of this syndrome is complete or partial absence of cerebellar vermis. The Dandy walker complex is a genetically sporadic disorder that occurs one in every 30,000 live births.[17] It is named for Walter Dandy and Arthur Earl Walker.

Agenesis of corpus callosum is the most common CNS anomaly associated with Dandy-Walker syndrome,[5,6,8,11] anomalies include microcephaly, cerebral gyral abnormalities, heterotopias, syringomyelia, malformations of the brainstem, aqueductal stenosis, Klippel-Feil deformity, six 
lumbar vertebrae, subdural hygroma, and cranium bifidum.[6,8,13] Only few cases of Dandy-Walker syndrome associated with occipital meningocele orencephalocele have been reported:[4,9,14,16]

Jim A et al" reviewed 11 cases of Dandy-Walker syndrome associated with occipital encephalocele, finding the encephalocele communicated with the posterior fossa cyst in eight cases.

Recently, Bindal et al.' found eight cases of associated occipital meningocele in their series of 50 cases of Dandy Walker syndrome, suggesting that this anomaly is not so rare. However, such a large occipital meningocele as in our case has never been described.

In all previous cases, the associated occipital meningocele was not the main issue of therapy. Bindal et al even reported that the occipital meningocele disappeared after shunting without surgical repair in two patients. In contrast, the occipital meningocelein our case was formed by the huge Dandy-Walker cyst and was the major threat to the patient's survival.

Several theories have been proposed for the pathogenesis of Dandy-Walker syndrome. The original theory was based on atresia of the foramina of Luschka and Magendie ${ }^{[2]}$ supposedly during the 8th week of embryonic life.[9]

This theory was later rejected on the basis that the cerebellar anlagen are fused in the midline before the foramina becomes patent [1] and because some patients demonstrated patent foramina.[3] Benda ${ }^{[3]}$ and others ${ }^{[6,13]}$ consider that this syndrome is a complex developmental anomaly, possibly of the fourth ventricle with membrane alterations and cleaving of the cerebellum.

Brodal and Hauglie Hanssen [1] believed that early bulging of embryonic membranes of the rhombencephalon prior to formation of foramina is the crucial abnormality. Carmel et al.[8] postulated that Dandy-Walker syndrome is a primary developmental anomaly that affects the closure of the neural tube at the level of the cerebellum before the 8th week of embryonic life, based on the complete absence of both the vermis and the choroid plexus in two of their 18 cases, structures which initially appear in the 7th to 8th embryonic week. In contrast, Padget, ${ }^{[7]}$ explained the syndrome as the result of reopening of the neural tube rather than failure to close.

The syndrome may also be a manifestation of a spectrum of neural tube defects resulting from over distention of the tube during development. These earlier hypotheses generally postulated the origin of this syndrome to occur quite early in embryonic life.

The associated occipital meningocele in our case suggests that Dandy-Walker syndrome may not be an early embryonal maldevelopment, but an event occurring much later than the closure of the neural tube. The exact pathogenesis of Dandy-Walker syndrome awaits further studies.

CONCLUSION: Dandy walker syndrome is a rare congenital anomaly with very few cases reported till date with associated occipital meningocele. Prognosis of this syndrome is improved recently with surgical intervention but mortality is high mainly associated with other CNS abnormalities.

\section{REFERENCES:}

1. Brodal A, Hauglie-Hanssen E: Congenital hydrocephalus with defective development of the cerebellar vermis (Dandy-Walker syndrome). J Neurol.

2. Dandy WE, Blackfan KD: Internal hydrocephalus an experimental, clinical and pathological study. Amer J Dis Child 1914; 8: 406-482.

3. Benda CE: The Dandy-Walker syndrome or the socalled atresia of the foramen Magendie. J Neuropath ExpNeurol 1954; 13: 14-29. 
4. Sautreaux JL, Giroud M, Dauvergne M, Nivelon JL, Thierry A: Dandy-Walker malformation associated with occipital meningocele and cardiac anomalies: A rare complex embryologic defect. J Child Neurol 1968; 1:64-66.

5. Raimondi AJ, Samuelson G, Yarzagaray L, Norton T: Atresia of the foramina of Luschka and Magendie: the Dandy-Walker cyst. J Neurosurg 1969; 31: 202-216.

6. Hart MN, Malamud N, Ellis WG: The Dandy Walker syndrome. A clinicopathological studybased on 28 cases. Neurology (Minneap) 1972; 22: 771-780.

7. Fischer EG: Dandy-Walker syndrome: An evaluation of surgical treatment. J Neurosurg 1973; 39: 615-621.

8. Carmel PW, Antunes JL, Hilal SK, Gold AP: Dandy-Walker syndrome: Clinico-pathological features and re-evaluation of modes of treatment. Surg Neuro 1977; 18: 132-138.

9. Saitoh K, Kawamoto T, Ebina T, Tanaka T: Sib cases of Dandy-Walker syndrome. No ToShinkei 1978; 30: 875-879.

10. Tal Y, Freigang B, Dunn HG, Durity FA, Moyes PD: Dandy-Walker syndrome: Analysis of 21 cases. Dev Med Child Neurol 1980; 22: 189-201.

11. Sawaya R, McLaurin RL: Dandy-Walker syndrome. Clinical analysis of 23 cases. J Neurosurg 1981; 55: 89-98.

12. Serlo W, Kirkinen P, Heikkinen E, Jouppila P: Ante and postnatal evaluation of the DandyWalker syndrome. Childs New Syst 1985; 1: 148-151.

13. Golden JA, Rorke LB, Bruce DA: Dandy-Walker syndrome and associated anomalies. Pediatr Neurosci 1987; 13: 38-44.

14. Suzuki Y, Mimaki T, Tagawa T, Seino Y, Ohmichi M, Sugita N, Morimoto K, Yoshimine T: Dandy Walker cyst associated with occipital mening-ocele. PediatrNeurol 1989; 5: 191-193.

15. Bindal AK, Storrs BB, McLone DC: Management of the Dandy-Walker syndrome. PediatrNeurosurg. 1990; 16:163-169.

16. Bindal AK, Storrs BB, McLone DG: Occipital meningoceles in patients with the Dandy-Walker syndrome. Neurosurgery 1991; 28: 844-847.

17. Osenbach RK, Menezes AH. "Diagnosis and management of the Dandy-Walker malformation: 30 years of experience.". Pediatr Neurosurg 1992; 18(4): 179-89.

Axial section of the brain shows dilated lateral ventricles:

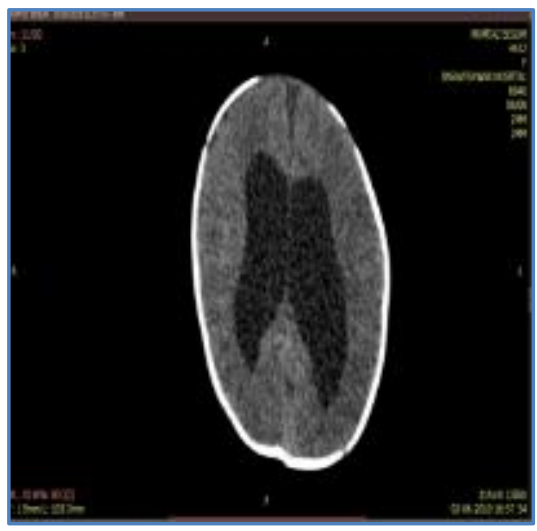

Fig. 1 


\section{CASE REPORT}

Axial section of the brain shows dilated lateral and third ventricles with a posterior fossa cyst:

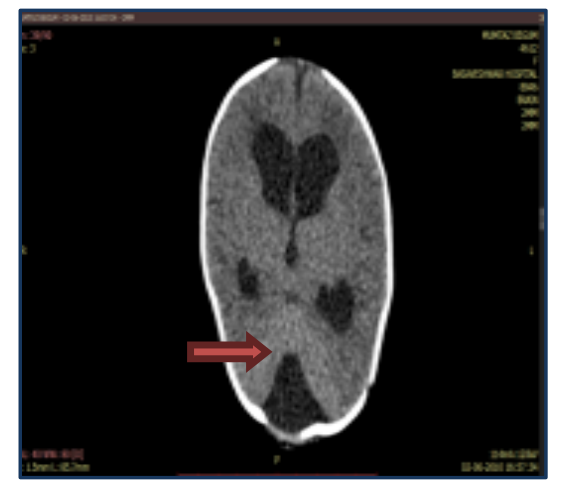

Fig. 2

Axial sections of the brain shows dilated ventricular system with a posterior fossa cyst communicating with the fourth ventricle on one side and occipital meningocele on the other end(key hole appearance):

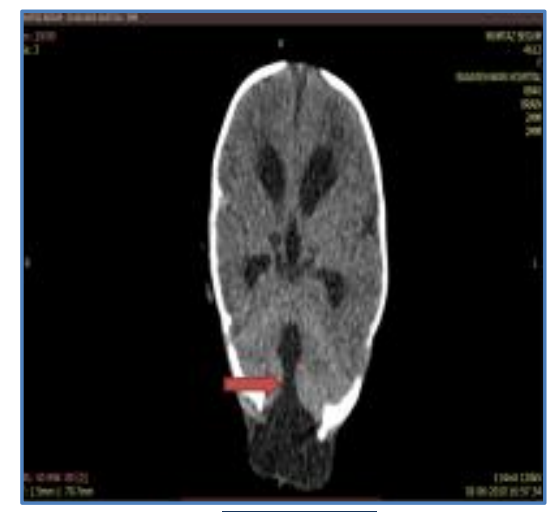

Fig. 3

Axial sections of the brain shows dilated ventricular system with a posterior fossa cyst communicating with the fourth ventricle on one side and occipital meningocele on the other end:

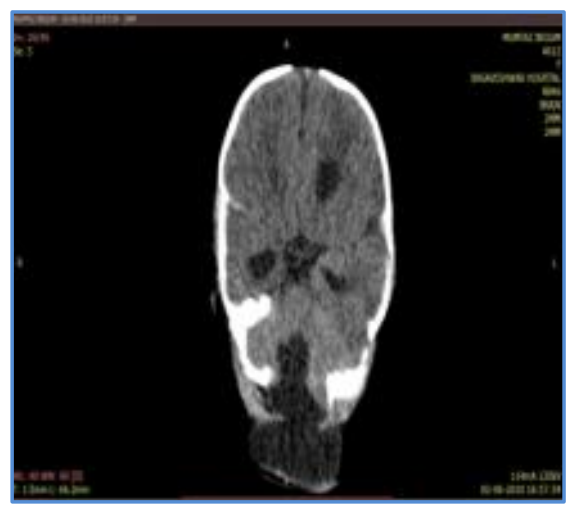

Fig. 4 


\section{CASE REPORT}

Sagittal images of brain showing posterior fossa cyst communicating with fourth ventricle on one side and occipital meningocele on the other:

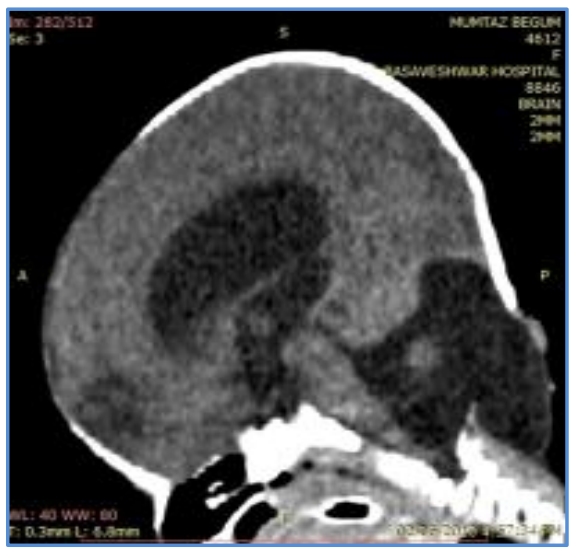

\section{Fig. 5}

Sagittal images showing posterior fossa cyst and occipital meningocele:

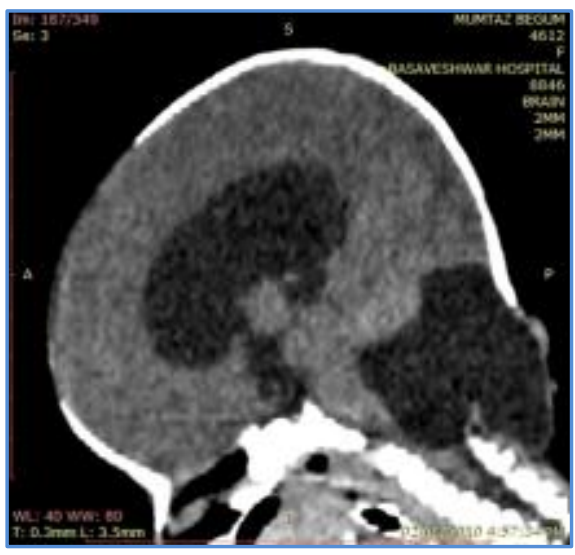

\section{Fig. 6}

\section{AUTHORS:}

1. Shrishail S. Patil

2. Apoorva Rampure

\section{PARTICULARS OF CONTRIBUTORS:}

1. Associate Professor, Department of Radiodiagnosis, MRMC, Basaveshwara Teaching and General Hospital, Gulbarga.

2. Post Graduate Resident, Department of Radiodiagnosis MRMC, Basaveshwara Teaching and General Hospital, Gulbarga.

\section{NAME ADDRESS EMAIL ID OF THE} CORRESPONDING AUTHOR:

Dr. Apoorva Rampure, Jaideep Building, P.D.A. Engineering College Road, Aiwan-E-Shahi, Gulbarga 585102.

Email: apoorvarampure19@gmail.com

Date of Submission: 19/08/2014. Date of Peer Review: 20/08/2014. Date of Acceptance: 27/08/2014. Date of Publishing: 05/09/2014. 